\title{
Vestibular Alveolar bone height measurement: Accuracy and Correlation between direct and indirect techniques
}

\author{
Guillermo Pérez-Sánchez' , Maykel González-Torres², \\ Mario A. Guzmán-Espinosa', Víctor Hernández-Vidal', \\ Bernardo Teutle-Coyotecatl' ' Luz V. Mendoza-García, \\ Angeles Moyaho-Bernal ${ }^{1}$

\footnotetext{
'Benemérita Universidad Autónoma de Puebla, Facultad de Odontología, Departamento de Ortodoncia, Puebla, Mexico.

${ }^{2}$ Consejo Nacional de Ciencia y Tecnología (Conacyt)-Laboratorio de Biotecnología, Instituto Nacional de Rehabilitación "Luis Guillermo Ibarra", Ciudad de México, México.
}

\begin{abstract}
Cone Beam Computed Tomography (CBCT) has modified the perspective of dentistry images, providing manipulable threedimensional images with a 1:1 patient:image ratio. Treatments and diagnosis are modified or corroborated by CBCT; however, its accuracy in thin structures such as cortical bone has been subjected to critical review. The aim of this study is to correlate the measurement of vestibular alveolar bone height using direct measurements and measurements performed with cone-beam tomographic images with standard (SD) voxel resolution. Thirty incisor and premolar teeth of patients undergoing open curettage were measured with a high-precision caliper and with Cone Beam Computed Tomography (CBCT) at an SD resolution of $0.16 \mathrm{~mm}$ voxels in a $3 D$ Orthophos $X G$ Sirona
\end{abstract}

scanner. Intra-observer evaluation was performed using the intraclass correlation coefficient (ICC). Direct measurements and $C B C T$ measurements were correlated using Pearson correlation (PCC). The mean difference between indirect and direct measurements was $3.15 \mathrm{~mm}$. Paired t test and Pearson Correlation coefficient determined that all measurements differed statistically from each other with $p<0.05$. With the CT scanner and protocol used in this study, CBCT images do not enable accurate evaluation of vestibular alveolar bone height.

Received: December 2019; Accepted: January 2020.

Keywords: computed tomography, cone-beam, diagnostic imaging, alveolar bone loss, tooth.

\section{Medición de la altura del hueso alveolar vestibular: precisión y correlación entre técnicas directa e indirecta}

\begin{abstract}
RESUMEN
La tomografia de haz cónico (CBCT) ha modificado la perspectiva de la imagenología en odontología que brinda una imagen tridimensional manipulable con una relación 1:1, paciente: imagen. Los tratamientos y diagnósticos se ven modificados o corroborados por el CBCT; sin embargo, la exactitud que presenta en estructuras delgadas como las corticales óseas ha sido sometida a críticas. El objetivo fue correlacionar la medición de la altura del hueso alveolar vestibular mediante mediciones directas y las realizadas con imágenes tomográficas de haz cónico con resolución de vóxel estándar (SD). Treinta dientes incisivos y premolares de pacientes sometidos a un curetaje abierto se midieron con un calibrador de alta precisión y una tomografia computarizada de haz cónico (CBCT) a una resolución SD de
\end{abstract}

\section{INTRODUCTION}

Orthodontic treatments use 2D X-rays as a fundamental part of diagnosis to determine dental or bone injury, pathologies, root parallelism, tooth inclinations,
0,16 mm de vóxeles en un escáner $3 D$ Orthophos XG Sirona. La evaluación intraobservador se realizó utilizando el coeficiente de correlación intraclase (ICC), y las mediciones directas y las mediciones $C B C T$ se correlacionaron utilizando la correlación de Pearson (PCC). La diferencia media entre las mediciones indirectas y directas fue de 3,15 $\mathrm{mm}$. La prueba t pareada y el Coeficiente de Correlación de Pearson determinaron que todas las mediciones fueron estadisticamente diferentes entre sí con una $p<0.05$. Con el escáner de TC y el protocolo utilizado en este estudio, las imágenes CBCT no permiten una evaluación precisa de la altura del hueso alveolar vestibular.

Palabras clave: tomografía computarizada, haz cónico, diagnóstico por imagen, pérdida de hueso alveolar, diente.

and growth during treatment ${ }^{1}$. In dentistry, 3D radiology complements this tool. The company Quantitative Radiology (Verona, Italy) introduced the first Cone Beam Computed Tomography (CBCT) 
for dental use in the year 2000 in Loma Linda University, USA ${ }^{2}$. This new tool has significant advantages such as low radiation dose, a 1:1 ratio of bone structures and shorter shooting times than 2D X-rays and computed axial tomography (CAT). The companies involved in 3D tomography have provided different options to the orthodontist, making it important to analyze each tomogram and corroborate the accurate measurement of anatomical structures. The 1:1 ratio has been demonstrated in many cases; however, when highly accurate measurement of thin structures is required for cortical bone, the reliability of $3 \mathrm{D}$ tomography decreases ${ }^{3,4}$.

The alveolar bone is formed by the projection of the external and internal cortical bone and provides support to the teeth and soft tissues. The determination of alveolar bone height helps to establish the limitations in orthodontic treatments, e.g., in biomechanical expansion or closure of spaces, movements could cause or aggravate fenestrations or dehiscences in the alveolar crest, especially if the diagnosis was incorrect. Biomechanical and biological factors are closely related and determine the collateral effects of potential treatment such as root resorption, gingival recession, dehiscence and fenestrations ${ }^{5,6}$.

Three-dimensional imaging through a CBCT scan is important because it can reveal fenestrations and dehiscences. These types of alveolar defects are common, especially in hyper-divergent patients and increased lower facial height ${ }^{7,8}$. A previous study of 1872 teeth reported high prevalence of these defects in hyper-divergent $(8.35 \%)$ and normo-divergent $(8.18 \%)^{6}$ subjects. In another study, i-CAT ${ }^{\mathrm{TM}}$ was performed on 123 scans, showing that the presence of fenestrations and dehiscences did not vary significantly between skeletal I, II or III malocclusion ${ }^{9}$.

In terms of measurements on CBCT, it has been found that linear measurements are reliable, but the presence of soft tissue and voxel size influenced the results. Even when using a $0.125 \mathrm{~mm}$ voxel, the thin vestibular cortex of some external layers is not represented, hence, there is a considerable risk of overestimating the dehiscences or fenestrations viewed in a three-dimensional image ${ }^{10}$.

The correlation between linear measurements performed on a skull and the same measurements taken from tomographic images analyzed using
Dolphin $^{\circledR}$ software has been assessed in the literature. It was demonstrated that many of the linear measurements differed significantly ${ }^{11}$. This highlighted the limitations of using this technology for studies in skulls. Several factors can influence the accuracy of the results, such as the attenuation of soft tissues, metal-based restorations and patient movement.

CBTC scans ( $0.4 \mathrm{~mm}$ voxel) were performed in pig jaws to measure the height of the vestibular alveolar bone in the molar region. The results showed that tomographic images can overestimate alveolar bone loss associated with rapid palatal expansion by 1.5 to $2 \mathrm{~mm}^{12}$.

The aim of this study was to investigate whether there is a significant correlation in the accuracy of the vestibular alveolar bone height measurement between direct and indirect techniques $(0.16 \mathrm{~mm}$ voxel resolution CBCT), with the goal of validating this methodology and establishing its limitations.

The importance of the present study is the observation of variables in living patients, and analysis of the representation of clinical reality in CBCT scans.

\section{MATERIALS AND METHODS}

This study was reviewed and approved by the Faculty of Dentistry Research Committee at the Benemérita Universidad Autónoma de Puebla (Mexico). The procedures adhered to ethical standards and there was no risk in the investigation according to the Regulation of the General Health Law on Research and Helsinki Declaration guidelines for research involving human subjects.

The intraclass correlation coefficient for the vestibular alveolar bone height measurements of both researchers was 0.980 . The inter-researcher's Pearson's correlation coefficient for the direct technique (Vernier caliper measurement) was 0.990, and for the indirect technique (CBCT at $0.16 \mathrm{~mm}$ ) it was 0.986 . Thus, direct and indirect measurements were consistent and reproducible for each researcher.

Eight patients were invited to participate in the study, under informed consent, to receive open curettage treatments. The protocol included a sample of 30 teeth that were exposed to a fullthickness flap during debridement. The study included incisors and premolars of patients of different ages and genders, and excluded 
teeth with extensive restorations that could affect the tomographic image.

The procedure included patients who required flap elevation for their periodontal procedure which enabled us to perform the measurements. A copy of the CBCT scan was delivered to the specialist who was treating the patients for diagnostic purposes without additional cost.

Patients were exposed to one CBCT scan after clinical procedures. Precautions were taken to minimize the radiation dose, in view of the "As Low as Reasonably Achievable" (ALARA) principles. Exposure time was kept as short as possible, good hygiene practices were followed and proper use was made of personal protective equipment such as lab coats, disposable gloves and safety glasses. The design and execution of this study were subjected to Institutional Review Board oversight (IRB). Patients who were scheduled to receive radiation from cone-beam tomographic images were prospectively enrolled in an IRBapproved study.

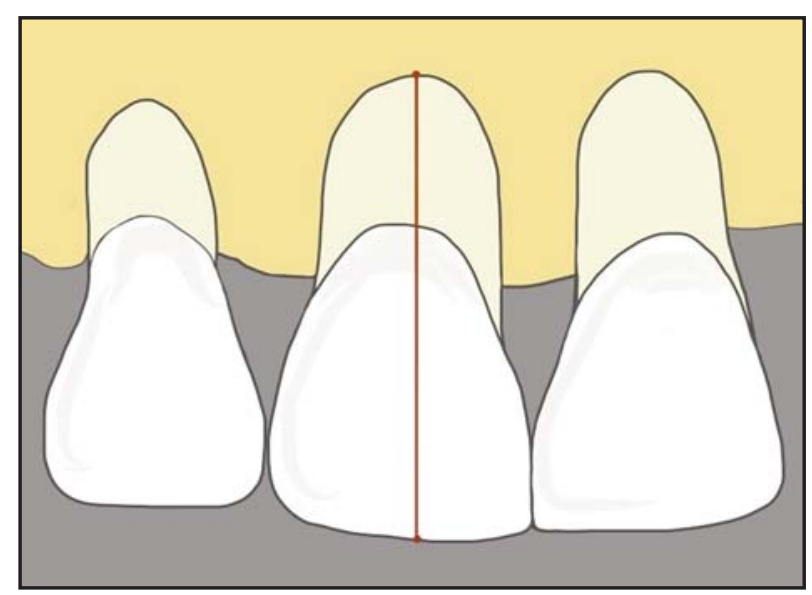

Fig. 1: Direct measurement technique.

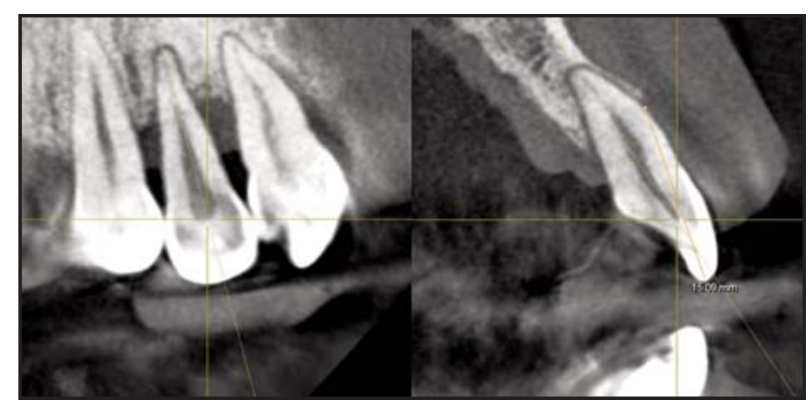

Fig. 2: Indirect measurement technique.

\section{Direct measurement technique}

Once the flap was performed and after elimination of dental calculus, the height of the vestibular alveolar bone was measured from the incisal, occlusal edge or the vestibular cusp, along the longitudinal axis of the tooth to the end of the observable vestibular alveolar bone using a digital Vernier caliper Stainless Steel Professional, with an error range of $0.01 \mathrm{~mm}$. Three independent measurements were carried out by two researchers before the periodontist placed the suture (Fig. 1).

\section{Indirect measurement technique}

Subsequently, the patient was taken to the radiology department to perform the image study using an Orthophos XG 3D Sirona ${ }^{\circledR}$ scanner. This study was conducted according to the specifications suggested by the manufacturer: 12 $\mathrm{mA}, 90 \mathrm{kVp}$ and 14.9 -second exposure ${ }^{13}$. The field of view of the CBCT scans was $8 \times 8 \times 8 \mathrm{~cm}$, with a resolution of $0.16 \mathrm{~mm}$. The tooth was placed in axial, frontal and transverse views, taking care that the resulting tomographic sections always followed the longitudinal axis of the tooth. Using the measurement tool in the software, the digital ruler was placed from the incisal or occlusal edge to the end of the observable vestibular alveolar bone, as shown in Fig. 2. This measurement was repeated three times. An indirect measurement of the vestibular alveolar bone height of each tooth was previously measured directly.

The Kolmogorov-Smirnov test was employed to assess the data distribution. Means and standard deviations were calculated, and bivariate analysis, Pearson's correlation coefficients and paired $t$ test were used to establish the significance of differences between the measurements. All the data were analyzed using IBM SPSS Statistics version 22 software. Tests were applied with $\mathrm{p} \leq 0.05$ level of significance.

\section{RESULTS}

The vestibular alveolar bone height based on 30 measurements for the direct technique (Vernier caliper measurement) was $11.92 \pm 2 \mathrm{~mm}$, while for the $\mathrm{CBCT}$ indirect technique at $0.16 \mathrm{~mm}$, it was $15.07 \pm 4 \mathrm{~mm}$ (Table 1). Mean dehiscences were overestimated by $3.15 \mathrm{~mm}(26 \%)$ on CBCT. 
Paired $\mathrm{t}$ test demonstrated significant differences between direct measurement and SD CBCT $(\mathrm{p}=$ 0.001 ), as shown in Table 2.

Pearson's correlation coefficient (PCC) between direct and indirect measurements was 0.68 , which is statistically significant $(\mathrm{P}<0.001)$ and indicates that linear correlation between parameters was moderate.

\section{DISCUSSION}

Cone beam computed tomographic (CBCT) imaging has emerged as an important supplemental radiographic technique in different areas. In this study, low-resolution CBCT values differed significantly from the values measured using Vernier caliper. Even though the voxel size of the CBCT Orthophos XG 3D is one of the smallest and most accurate available, the results of this study are consistent with those of Sun et al. ${ }^{12}$, who reported discrepancies of up to $2 \mathrm{~mm}$ between direct and indirect measurements. The current study showed discrepancies of up to $3 \mathrm{~mm}$ between techniques, probably due to the thinness of the cortical layer.

Leung et al. ${ }^{4}$ compared direct and indirect measurements, finding a threefold higher incidence of fenestrations when measuring using CBCT compared to direct measurement, and more false positives. There were also false negatives in which CBCT showed no real defects, with more than half of the dehiscences not detected by CBCT.

However, Patcas et al. ${ }^{10}$ and Timock et al. ${ }^{14}$ found no significant difference between direct and indirect measurements. The importance of the current study is that it considers the variables present in a living patient and shows the clinical reality of the tomograms. These variables may generate discrepancies between studies, as may other factors related to the in vitro technique, such as alcohol, glutaraldehyde or formaldehyde fixation, the presence or absence of restorations and soft tissues, or the nonexistent movement of the corpse or skull, all of which can generate changes in the density and architecture of the periodontium at the time of the $\operatorname{scan}^{1,3,4,10,14}$. However, the position of the skull does not affect the accuracy of the linear measurements ${ }^{2}$.

This study used the standard specifications provided by the manufacturer: $12 \mathrm{~mA}, 90 \mathrm{kVp}$ and 14.9-second exposure, according to the scanner user manual ${ }^{13}$. Misch et al. suggested that in vivo studies should be undertaken as in previous studies that employed $47.7 \mathrm{~mA}, 120 \mathrm{kVp}$ and a 20 -second exposure ${ }^{15}$; or $98 \mathrm{~mA}, 120 \mathrm{kVp}$ and a 20 -second exposure ${ }^{16}$. Both studies showed that all alveolar defects (artificially created in vitro) were detected with high precision, although the radiation level was significantly increased. However, other studies used different values, such as: 1-3 mA, $7 \mathrm{~mA}, 2 \mathrm{~mA}$ and for example, $80 \mathrm{kVp}$ and a 17-second exposure, or $0.5 \mathrm{~mA}, 110 \mathrm{kVp}$ and a 5-7-second exposure, and obtained results with low accuracy and sensitivity ${ }^{12,17,18}$.

In addition, the use of $\mathrm{CBCT}$ as a reference standard is not appropriate, since all scanners showed errors in the measurements. The study explains that the lack of soft tissue affects the final image and the presence of tissue generates attenuation coefficients that affect image sharpness.

This study was conducted in periodontally compromised patients. Healthy patients might have longer

\begin{tabular}{l|c|c|}
\hline $\begin{array}{l}\text { Table 1: Descriptive statistics of direct and indirect } \\
\text { measurements of vestibular alveolar bone } \\
\text { height. }\end{array}$ \\
\hline & $\begin{array}{c}\text { Direct measurement } \\
\mathbf{X}=30 \mathrm{~mm}\end{array}$ & $\begin{array}{c}\text { Indirect measurement } \\
\mathbf{X}=30 \mathrm{~mm}\end{array}$ \\
\hline $\begin{array}{l}\text { Mean } \pm \text { standard } \\
\text { deviation }\end{array}$ & $(11.92 \pm 2)$ & $(15.07 \pm 4)$ \\
\hline Minimum & $(8.58 \pm 0.01)$ & $(9.04 \pm 0.01)$ \\
\hline Maximum & $(15.92 \pm 0.01)$ & $(20.18 \pm 0.01)$ \\
\hline Range & $(7.34 \pm 0.01)$ & $(11.14 \pm 0.01)$ \\
\hline $\begin{array}{l}\text { Mean (average) } \\
\text { difference }\end{array}$ & Reference standard & $+(3.15)$ \\
\hline
\end{tabular}

\begin{tabular}{|c|c|c|c|c|c|c|c|}
\hline $\begin{array}{l}\text { Technique } \\
\text { comparison }\end{array}$ & $\begin{array}{l}\text { Mean } \\
\text { value }\end{array}$ & $\begin{array}{l}\text { Standard } \\
\text { deviation }\end{array}$ & $\begin{array}{l}\text { Standard } \\
\text { error }\end{array}$ & $\begin{array}{l}\text { Lower } \\
\text { limit }\end{array}$ & $\begin{array}{l}\text { Upper } \\
\text { limit }\end{array}$ & $t$ & $\begin{array}{c}\text { Bilateral } \\
\text { significance }\end{array}$ \\
\hline Vernier - СВСТ & -3.1 & 2.7 & 0.50 & -4.2 & -2.1 & -6.3 & 0.001 \\
\hline
\end{tabular}


and thinner cortical bones, which would be even more difficult to detect by CBCT.

The use of CBCT images to measure the vestibular alveolar bone of incisors and premolars provides inaccurate results when using SD resolutions in the Orthophos XG 3D (0.16 mm voxel), since it over estimates the size of dehiscences by an average $3.15 \mathrm{~mm}$. SD CBCT measurements differed significantly from values measured with Vernier caliper.

\section{ACKNOWLEDGMENTS}

We thank Benemérita Universidad Autónoma de Puebla (BUAP) and Universidad Popular Autónoma del Estado de Puebla (UPAEP) for supporting this joint research project; Juan Carlos Castillo Sánchez and María del Rocío Pedraza Espejel for technical assistance, and patients of the Oral Rehabilitation Clinics of both universities for their participation.

\section{FUNDING}

None

\section{REFERENCES}

1. Fleiner J, Hannig C, Schulze D, Stricker A, Jacobs R. Digital method for quantification of circumferential periodontal bone level using cone beam CT. Clin Oral Investig 2013; 17:389-396.

2. Berco M, Rigali Jr PH, Miner RM, DeLuca S, Anderson NK, Will LA. Accuracy and reliability of linear cephalometric measurements from cone-beam computed tomography scans of a dry human skull. Am J Orthod Dentofacial Orthop 2009; 136:17-18.

3. Mischkowski R A, Pulsfort R, Ritter L, Neugebauer J, Brochhagen H G, Keeve E, Zöller J. E. Geometric accuracy of a newly developed cone-beam device for maxillofacial imaging. Oral Surg Oral Med Oral Pathol Oral Radiol Endod 2007; 104:551-559.

4. Leung CC, Palomo L, Griffith R, Hans MG. Accuracy and reliability of cone-beam computed tomography for measuring alveolar bone height and detecting bony dehiscences and fenestrations. Am J Orthod Dentofacial Orthop 2010; 137: 109-119.

5. Karring T, Nyman S, Thilander B, Magnusson I. Bone regeneration in orthodontically produced alveolar bone dehiscences. J Periodontal Res 1982; 17:309-315.

6. Enhos S, Uysal T, Yagci A, Veli İ, Ucar FI, Ozer T. Dehiscence and fenestration in patients with different vertical growth patterns assessed with cone-beam computed tomography. Angle Orthod 2012; 82:868-874.

7. Beckmann S, Kuitert RB, Prahl-Andersen B, Segner D, The $\mathrm{R}$, Tuinzing D. Alveolar and skeletal dimensions associated with lower face height. Am J Orthod Dentofacial Orthop 1998; 113:498-506.

8. Gracco A, Lombardo L, Mancuso G, Gravina V, Siciliani G. Upper incisor position and bony support in untreated patients as seen on CBCT. Angle Orthod 2009; 79:692-702.

9. Yagci A, Veli İ, Uysal T, Ucar FI, Ozer T, Enhos S. Dehiscence and fenestration in skeletal Class I, II, and III malocclusions assessed with cone-beam computed tomography. Angle Orthod 2011; 82:67-74.
Likewise, the Pearson correlation between the two techniques was 0.68 , indicating a moderate correlation. This result confirms the overestimation of the descriptive statistics.

CBCT has proven its accuracy for the measurement of bone structures, but its ability to detect the thin cortical bones and determine alveolar bone height is poor. It is therefore recommended that this tool, which still has limitations, should not be used as a determining factor in treatment, but as an aid to diagnosis.

\section{CORRESPONDENCE}

Dr. Angeles Moyaho Bernal

Facultad de Estomatología de la Benemérita

Universidad Autónoma de Puebla.

Calle 31 poniente \#1304. Col. Los Volcanes,

C. P. 72410 . Puebla, México

angeles.moyaho@correo.buap.mx
10. Patcas R, Müller L, Ullrich O, Peltomäki T. Accuracy of cone-beam computed tomography at different resolutions assessed on the bony covering of the mandibular anterior teeth. Am J Orthod Dentofacial Orthop 2012; 141:41-50.

11. Periago DR, Scarfe WC, Moshiri M, Scheetz JP, Silveira AM, Farman AG. Linear accuracy and reliability of cone beam CT derived 3-dimensional images constructed using an orthodontic volumetric rendering program. Angle Orthod 2008; 78:387-395.

12. Sun Z, Smith T, Kortam S, Kim D-G, Tee BC, Fields H. Effect of bone thickness on alveolar bone-height measurements from cone-beam computed tomography images. Am J Orthod Dentofacial Orthop 2011; 139:117-127 .

13. Company STD. Manual del operador ORTHOPHOS XG 3D / Ceph, ORTHOPHOS XG 3 Dready / Ceph. Germany: Dental Systems GmbH. 2013.

14. Timock A M, Cook V, McDonald T, Leo M C, Crowe J, Benninger B L, Covell Jr D A. Accuracy and reliability of buccal bone height and thickness measurements from conebeam computed tomography imaging. Am J Orthod Dentofacial Orthop 2011; 140:734-744.

15. Misch KA, Erica SY, Sarment DP. Accuracy of cone beam computed tomography for periodontal defect measurements. J Periodontol 2006; 77:1261-1266.

16. Pinsky H, Dyda S, Pinsky R, Misch K, Sarment D. Accuracy of three-dimensional measurements using conebeam CT. Dentomaxillofac Radiol 2006; 35:410-416.

17. Hilgers ML, Scarfe WC, Scheetz JP, Farman AG. Accuracy of linear temporomandibular joint measurements with cone beam computed tomography and digital cephalometric radiography. Am J Orthod Dentofacial Orthop 2005; 128: 803-811.

18. Hintze H, Wiese M, Wenzel A. Cone beam CT and conventional tomography for the detection of morphological temporomandibular joint changes. Dentomaxillofac Radiol 2007; 36:192-197. 